\title{
¿QUÉ SON Y CÓMO SE FORMAN LOS VALORES?
}

What are values and how are they formed?

\author{
Diego Sánchez Meca \\ UNED
}

\begin{abstract}
Resumen: Para Nietzsche, la moral y sus valores no surgen de una conciencia innata ni de una razón «pura» que debe cumplir sus ideales en lucha con los instintos y las inclinaciones naturales, como enseñaba Kant, sino que la moral es una de las creaciones humanas que surge como respuesta a determinadas exigencias de la dinámica vital e histórica de los seres humanos en su lucha por la existencia y desde su necesidad de adaptarse al medio y desarrollarse. En todas las sociedades, el proceso de hominización, o sea, el acceso a la cultura, y con él la superación de la animalidad, se ha llevado a cabo mediante un tipo u otro de educación moral, que es la encargada de dar forma al caos de los impulsos vitales naturales del individuo.

Palabras clave: moral - valores - evolución - Darwin
\end{abstract}

AвSTRACT: For Nietzsche, morality and values do not arise from an innate conscience nor a «pure» reason which must struggle with instincts and natural inclinations, as Kant taught, but morality is a human creation as a response to certain requirements of vital and historic dynamic of humans in their struggle for existence and from their need to adapt to the environment and develop. In all societies, the process of humanization, that is, access to culture and the overcoming of animality, was carried out by one or another type of moral education, which is responsible for shaping the chaos of the natural life of the individual's instincts.

Keywords: Morals - Values - Evolution - Darwin

\section{1}

Es interesante empezar observando cómo, en el lenguaje común, la palabra valor designa, sobre todo, el precio de las cosas, tanto de las cosas materiales como de las personas. Hobbes, un pensador de gran sentido común, decía que «el valor de un hombre es como el de cualquier otra cosa, o sea, su precio, lo que alguien estaría dispuesto a pagar por el uso de sus facultades. El hombre no es un valor en sí ni tiene un valor absoluto, sino que depende de la necesidad y del juicio de los demás. Por ejemplo, un buen guerrero hábil en el manejo de las armas es de alto valor en tiempos de guerra, presente o inminente, pero vale mucho menos

1. Este es el texto de una conferencia pronunciada en el Palacio Bellas Artes de la Ciudad de México el 14 de marzo de 2012. 
en tiempo de paz»². En cualquier caso, valor es lo que debería ser o de hecho es objeto de preferencia y de deseo. Por ejemplo, valores son la riqueza, la salud, la fama, la fuerza, la belleza, la inteligencia, la nobleza, y cosas así.

Este término de valor entra en la filosofía moral bastante tarde, a finales del siglo xix y comienzos del xx, y se lo introduce para designar lo que debe ser objeto de preferencia moral. Antes se hablaba de los bienes, y fue, en realidad, Kant el primero que hizo la equiparación entre bien y valor en su Crítica del juicio donde dice: "Cada uno llama bien a lo que aprecia, y aprueba aquello en lo que encuentra un bien objetivo» ${ }^{3}$. Como Kant pensaba que los valores o los bienes son algo objetivo, en esta supuesta o postulada objetividad de los bienes se apoyaría la universalidad de los valores, que serían tales para todos los seres racionales.

Así que la ética de los valores o la filosofía de los valores, propiamente dicha, se desarrolla en la primera mitad del siglo xx, una época históricamente muy conflictiva, dramática y aterradora, tal como lo demostraron las dos guerras mundiales. Hay, por tanto, un contexto de miedo, y eso lleva a algunos filósofos a afirmar una concepción de los valores morales como entidades metafísicas, en sí, trascendentes y a priori. Por ejemplo, Windelband define los valores como «el deber ser en sí de una norma que confiere verdad, bondad y belleza a los comportamientos que se ajustan a ella $»^{4}$.

El problema que se le planteaba, sin embargo, a esta nueva metafísica axiológica era el de cómo explicar la relación de estos valores eternos con el hombre sensible y finito. Es decir, si los valores son trascendentes, entonces cómo se relaciona el hombre con ellos, ¿̇cómo los conoce para poder guiarse por ellos? Y sobre todo, ¿cómo entidades universales y eternas como estos valores absolutos pueden constituir una misma regla para la multiplicidad y mutabilidad de las situaciones empíricas en las que tiene que aplicarse? Entonces, para responder a estas cuestiones, se vuelven a repetir las aporías que ya a Platón se le presentaban cuando intentó explicar la relación entre sus ideas suprasensibles y el mundo de las apariencias. Llama la atención que un planteamiento filosófico tan anacrónico no fuera sólo cosa de filósofos de segunda fila, sino que vinieran a recaer también en él en parte figuras relevantes como Max Scheler. Pues Max Scheler defendía la tesis de que, aunque los valores trascendentes son inaccesibles al intelecto humano, en cambio el ser humano puede alcanzarlos a través del sentimiento o la intuición sentimental. En su obra Esencia y formas de la simpatía, Scheler defiende precisamente esta tesis de que el valor es el objeto intencional del sentimiento como las esencias son el objeto intencional del conocimiento. Como el miedo crecía en Europa por los años treinta y cuarenta, la filosofía de los valores fue tomando giros, después de Scheler, aún más metafísicos y teológicos. Por ejemplo, es ilustrativo el lenguaje que emplea René Le Senne, en su obra Obstáculo y valor, cuando dice que los valores son como «Dios-con-nosotros». Es decir, son trascendentes, únicos y eternos, pero están en relación con nosotros como lo está Dios, para iluminarnos y guiarnos ${ }^{5}$.

2. Th. Hobbes, Leviatán, I $₫ 10$.

3. I. Kant, Crítica del juicio, $\mathbb{} 5$.

4. W. Windelband, Präludien, Aufsätze und Reden zur Einleitung in die Philosophie, Tübingen/ Leipzig: J. C. B. Mohr, 1903, p. 43.

5. R. Le Senne, Obstacle et valeur, Paris: Aubier, 1934, p. 220. 
Bien, después de esto yo no hay mucho más que decir de esta filosofía de los valores profesada por estos nuevos Santos Padres de la Iglesia, y ni siquiera creo que valga la pena que nos refiramos a los pensadores que reaccionaron a esta metafísica axiológica y la criticaron duramente como, por ejemplo, Dewey, que en su Teoría de los valores definió esta disciplina como el arte inteligente de las elecciones humanas sin más, es decir, como la consideración apropiada de las relaciones entre medios y fines. Es decir, para Dewey, la relación del hombre con los valores es simplemente una posibilidad de elección, lo que implica, para él, preferir unos y desechar otros en función de ciertos criterios de tipo pragmáti$\mathrm{Co}^{6}$. Naturalmente, entre estos pragmatistas y aquellos metafísicos se organizó la correspondiente polémica en la que los pragmatistas llamaron a los metafísicos integristas, y los metafísicos acusaron a los pragmatistas del vicio nefando de relativismo. Ello nos hace ver mejor aún la necesidad de construir un marco conceptual distinto que nos permita un tipo de comprensión más productiva y más adaptada a lo que la experiencia histórica y sociológica nos exige.

Lo que dejamos a un lado, por tanto, es la idea, tan generalizada todavía hoy, de que todo ser humano tendría en su interior, de manera innata, una conciencia moral que habría sido puesta ahí en su alma por Dios, y que le diría en cada momento lo que está bien y lo que está mal. El tener esta conciencia moral innata sería, además, lo que confiere al ser humano su dignidad como persona, distinguiéndole así del simple animal. Y entonces la moral, la moralidad se entiende como el comportamiento de someter los impulsos de nuestra parte animal a la razón, de modo que sólo nos guiemos por la razón, exclusiva del ser humano, aunque tengamos que estar contradiciendo sin descanso nuestros deseos, apetitos e impulsos procedentes de nuestra parte sensible. En realidad, este es el núcleo fuerte del modo metafísico y teológico de entender la moral y su sistema de valores, y que tiene como supuesto necesario y fundamental la creencia en que el ser humano, en la parte esencial de su ser que es su alma, es sobrenatural y trascendente.

Yo creo que este planteamiento debe ser dejado a un lado para intentar avanzar en una reflexión que se base, no en creencias religiosas ni en supuestos teológicos, sino en lo que nos aportan y nos dicen las ciencias actuales de modo que podamos establecer lo que podríamos llamar un enfoque científico de la moral. Darwin fue quien desalojó de la ciencia la idea del hombre como alma suprasensible, perteneciente a un mundo celestial, e introdujo la idea del ser humano como un animal más. Más evolucionado, ciertamente, pero un animal del que la ciencia no puede asegurar que lleve en su interior ninguna ley moral suprasensible puesta ahí por un Dios creador. De modo que lo que la filosofía moral tiene que hacer ahora no es intentar nuevas fundamentaciones metafísicas y teológicas de la moral, sino estudiarla como una parte más de la cultura de los pueblos y de las sociedades como lo son el arte, la política, la técnica o la ciencia misma. Es decir, lo que hay que hacer es investigar sus orígenes históricos y su evolución, apoyándose en lo que nos dicen al respecto las ciencias humanas, antropológicas e históricas.

Lo que se nos muestra entonces es que la moral y sus valores no surgen de una conciencia innata ni de una razón «pura» que debe cumplir sus ideales en lucha

6. Cf. J. Dewey, La teoría de la valoración, Madrid: Siruela, 2008. 
con los instintos y las inclinaciones naturales, como enseñaba $\mathrm{Kant}^{7}$, sino que la moral es una de las creaciones humanas que surge como respuesta a determinadas exigencias de la dinámica vital e histórica de los seres humanos en su lucha por la existencia y desde su necesidad de adaptarse al medio y desarrollarse.

Fue, por tanto, Darwin quien inició el giro decisivo necesario para una comprensión científica de la moral, y se le debe reconocer, por tanto, el mérito de haber librado al ser humano del esencialismo metafísico para reinsertarlo en el acontecer natural del mundo del que es parte constitutiva ${ }^{8}$. El hombre y la cultura son evolución, por lo que la moral debe ser estudiada y comprendida a partir de los motivos extramorales, o sea, vitales, que la producen. Para Darwin, el espíritu humano y las distintas esferas de la cultura, entre ellas la moral, son logros que se van configurando de manera progresiva a partir de los mecanismos que rigen la lucha por la existencia ${ }^{9}$. La tarea de la ciencia de la moral debe ser, en consecuencia, el estudio de la formación de la conciencia moral y de su evolución histórica, al hilo de un análisis del proceso de humanización y de la adquisición progresiva de las facultades humanas.

En este contexto, Darwin considera al instinto una noción fundamental como dispositivo que cumple en los seres humanos las mismas funciones de adaptación y de regulación que tiene en el resto de los organismos vivos. Es decir, los instintos, los impulsos, las tendencias, los sentimientos, las inclinaciones, las pasiones, todo ese mundo de los afectos, juega un papel decisivo en los comportamientos como instancias primeras de su motivación porque estimulan las acciones antes de que las ideas y las representaciones intelectuales intervengan. Así, a partir de esta noción de instinto, Darwin adopta las explicaciones empiristas inglesas sobre el origen de la moral, y en concreto la que había propuesto Hume en el siglo XVIII, según la cual la moral deriva de instintos sociales originarios como la simpatía y la benevolencia. Darwin explica esto del siguiente modo: Puesto que los seres humanos descendemos de animales que viven en sociedad, o sea, de las comunidades y grupos de primates, habríamos desarrollado desde los orígenes instintos sociales que nos impulsan a favorecer la supervivencia del grupo y las condiciones de su desarrollo y bienestar ${ }^{10}$.

Por tanto, tenemos ya estas dos afirmaciones como punto de partida para el estudio científico de la moral tal como Darwin lo plantea: 1) la moral deriva de instintos, y 2) esos instintos son instintos sociales. Pero concretando todavía un poco más, Darwin señala que, entre los instintos sociales, destaca el del amor recíproco entre los miembros del grupo como sentimiento de simpatía y de benevolencia, y es en estos instintos donde ve los orígenes del sentido moral. Por tanto, la conciencia moral habría aparecido al hilo mismo de la modificación que supuso el incipiente proceso de hominización respecto de la vida animal, y la necesidad de adaptarse al medio en el marco de una situación de convivencia competitiva entre grupos de seres humanos. Luego esos instintos morales primitivos - dice Darwin— se habrían ido fortaleciendo en función de la eficacia se-

7. Cf. I. Kant, Fundamentación de la metafísica de las costumbres, Madrid: Espasa, 1994, pp. 117-118.

8. Así se lo reconoce Nietzsche. Cf. FP III 34[73].

9. Cf. Ch. Darwin, The Descent of Man, I, IV.

10. Ibid. 
lectiva que demostraban tener en la lucha por la existencia, o sea, en función de la utilidad que reportaban a la comunidad. Y así se habría formado una jerarquía natural y originaria de valores morales en la que primaban los valores altruistas frente a los valores puramente personales y privados, los cuales no habrían podido desarrollarse sino mucho más tarde, cuando la seguridad y la supervivencia del grupo estaban ya mucho mejor garantizadas ${ }^{11}$.

Por otra parte, para dar razón del desarrollo de la moralidad a partir de estos instintos sociales en un nivel de hominización ya más avanzado, Darwin recurre al papel que juegan la memoria y la reflexión en la configuración de la moral, en cuanto responsables de la formación de los remordimientos y del sentido del deber. O sea, los remordimientos serían el recuerdo de la victoria de un instinto egoísta sobre un instinto social. Y el sentido del deber sería la proyección en el futuro del carácter prioritario del instinto social sobre cualquier otro instinto de carácter egoísta. De ahí la definición darwiniana del deber como la fuerza del instinto que expresa una condición esencial para la vida.

En cuanto al carácter de la moral en nuestras sociedades ya más evolucionadas y civilizadas, Darwin considera que en ellas se ha desarrollado del modo más elevado el instinto de simpatía, de tal modo que este instinto impulsa a los más fuertes a proteger a los más débiles, los cuales pueden a su vez sobrevivir y reproducirse. Por lo que esta transformación, debida al cambio de las condiciones de la lucha por la existencia, representaría una de las conquistas esenciales del ser humano evolucionado. En conclusión, toda la explicación darwiniana del origen natural de la moral parte de la necesidad de los hombres primitivos de sobrevivir y adaptarse al medio. De modo que las características de la moral se habrían configurado en función de esta lucha, de forma que cualquier variación en las condiciones de existencia y, por tanto, en los instintos sociales primitivos que regulan la organización de la convivencia, habría supuesto la modificación correspondiente del contenido de la moralidad ${ }^{12}$.

Es evidente que este enfoque de la moral que inaugura Darwin ofrece, sin duda, elementos muy novedosos e interesantes, pero se le podría reprochar con razón que peca de un exceso de optimismo en relación a su comprensión de la dinámica humana en las primeras fases de su evolución histórica. Concretamente

11. En realidad será Spencer quien extraiga las consecuencias de estas ideas: «Lo que pretendo es que la moral (la ciencia de la recta conducta) tenga por objeto determinado cómo y por qué ciertas formas de conducta son perjudiciales y otras beneficiosas. Estos resultados buenos y malos no pueden ser consecuencias accidentales de la constitución de las cosas, sino que deben ser consecuencias necesarias, y estimo que el cometido de las ciencias morales es deducir de las leyes de la vida y de las condiciones de existencia qué formas de acción tienden necesariamente a producir felicidad y qué otras a producir desgracia. Hecho esto, tales deducciones serán reconocidas como leyes de la conducta. Y habrá que ajustarse a ellas al margen de una estimación directa de la felicidad o del sufrimiento». H. Spencer, $A n$ Autobiography, Michigan: University of Michigan, 2009, p. 305.

12. Cf. Ch. Darwin, The Expression of the Emotions in Man and Animals, Londres: J. Murray, 1872 
Nietzsche, que parte y prolonga pero a la vez modifica sustancialmente este planteamiento de Darwin sobre la moral, le critica no haber tenido en consideración los muchos datos que aportaban ya ciencias como la etnografía, la prehistoria, la antropología cultural, la paleografía, y que trazaban, en conjunto, un panorama bien distinto de ese idílico altruismo y amor recíproco, impulsado por los instintos sociales de benevolencia y simpatía entre los hombres primitivos ${ }^{13}$. Nietzsche rectifica, por tanto, este aspecto de la teoría de Darwin y considera que el primer instinto o impulso que predomina en el ser humano primitivo y en las comunidades que se van formando no es el instinto social, sino el miedo. Es, pues, en el miedo donde hay que buscar el origen de la moral occidental: «Todas nuestras apreciaciones o son propias o adquiridas. Estas son las más numerosas. Pero, ¿̇por qué las adoptamos? Por miedo, porque nuestra prudencia nos aconseja aparentar que las tenemos por nuestras y nos habituamos a esta idea de suerte que acaba por ser nuestra segunda naturaleza. Así, hacer una apreciación personal no quiere decir valorar una cosa según el placer o el disgusto que nos causa... Estas determinaciones se nos crean durante la infancia y rara vez cambiaremos de opinión con respecto a ellas. Lo más frecuente es que durante toda nuestra vida sigamos siendo víctimas de los juicios infantiles a los que nos hemos habituado» ${ }^{14}$. En las fases prehistóricas, que es cuando se forma la moral, el miedo es la instancia instintiva que preside tanto la relación del hombre con la naturaleza como la relación del hombre con los demás hombres. Porque hay muchísimas cosas y procesos que escapan al control de los seres humanos primitivos, o sea, todo lo desconocido y todo lo que no puede ser previsto y controlado y que produce, consiguientemente, miedo. El ser humano prehistórico es un ser desprotegido y frágil frente a los muchos peligros que amenazan su supervivencia. De modo que el miedo es el mecanismo instintivo fundamental con el que él reacciona y trata de defenderse de esos peligros ${ }^{15}$. ¿Cómo lo hace? Es decir, ¿̇cómo defiende el miedo al ser humano primitivo de los innumerables peligros que le amenazan? Pues llevándole a establecer patrones de comportamiento que se ha comprobado que garantizan situaciones de seguridad, de autoprotección y de dominio estable de la convivencia, y luchando firmemente para mantenerlos estables y sin cambios. Estos esquemas de comportamiento fijados y defendidos contra cualquier cambio y cualquier novedad son las costumbres. La moral nace justamente para mantener estas costumbres. Y por eso, el contenido de la moralidad primitiva no es otro que el de la obediencia ciega a las costumbres ${ }^{16}$.

13. Cf. FW $\$ 345$.

14. $\mathrm{M} \ 104$.

15. «Nosotros los hombres de hoy, a causa de nuestras debilidades y de nuestra falta de experiencias serias, hemos llegado a ser ignorantes y fantásticos en comparación con una época del miedo - la época más larga de la humanidad-, en la que el individuo tenía que protegerse contra la violencia y se veía forzado, por ello, a ser violento él mismo. Entonces el hombre atravesaba una dura escuela de sufrimientos físicos y de privaciones, y encontraba en una cierta crueldad respecto de sí mismo, en un ejercicio voluntario del dolor, un medio necesario a su conservación. Entonces se educaba a las personas en la resistencia al dolor, se provocaba voluntariamente el dolor y se veía a los demás víctimas de los más grandes sufrimientos sin tener otro sentimiento que el de la propia seguridad». FW $\$ 48$.

16. "Ciertos instintos fuertes y peligrosos, como el placer de acometer empresas, la audacia loca, el ansia de venganza, la astucia, la rapacidad, la sed de poder, que antes tenían que ser no sólo 
Esta es una tendencia que forma parte constitutiva de nuestra moral tradicional, y que podemos ver todavía hoy, sobre todo, en los pueblos pequeños y entre gente menos evolucionada y refinada: se identifica la moral con la resistencia y oposición contra la influencia de lo nuevo, de lo individual, de lo que escapa a las costumbres y a la regla y, por tanto, de todo lo que es susceptible de amenazar la autoridad de los valores tradicionales. Ya desde su nacimiento, pues, la nuestra es una moral gregaria, o sea, una moral de la oposición a la excepción y del rechazo del individuo independiente, innovador, creativo y autónomo por miedo.

Pero hay una manera especialmente elocuente de poner en evidencia esta estrecha relación entre el miedo y nuestra moral gregaria, que es examinando, aunque sea brevemente, cómo hemos sido educados moralmente, o sea, cómo se ha producido en nosotros el proceso de grabación, de incorporación y de aprendizaje de las normas y valores de nuestra moral tradicional. Se ha tratado de un proceso de adiestramiento y de moralización en un conjunto de valores y de costumbres, en el que sólo se nos han transmitido sentimientos, o sea, reacciones afectivas de inclinación o de rechazo hacia determinados comportamientos, y no ideas ni conceptos: «Lo esencial e inestimable en toda moral es que es una coacción prolongada, el obedecer durante mucho tiempo y en una única dirección. Con esto se obtiene y se ha obtenido siempre, a la larga, la virtud» ${ }^{17}$. Esto ha sido así, en primer lugar, porque a la edad en que se educa moralmente a los individuos, estos no tienen todavía uso de razón, son niños. Y a los niños pequeños no se les puede todavía dar explicaciones, por ejemplo, de lo hermosa que es la decencia de determinadas costumbres, de su larga tradición, de su procedencia tal vez divina y de su bondad, en definitiva, para la sociedad mantenida y transmitida de generación en generación: «iUn bofetón al niño! y no volverá a repetir la acción. Por consiguiente, el bofetón es aquí un recordatorio de la lección aprendida: el dolor como el más intenso estimulante de la memoria» ${ }^{18}$. Pero, en segundo lugar, aunque se les pudiera explicar todo esto y ellos lo pudieran entender, los educadores de la moral saben que las explicaciones morales no

honrados - bajo nombres distintos, como es obvio, a los que acabamos de decir-, sino desarrollados y cultivados en un sentido de utilidad colectiva (porque cuando la comunidad estaba en peligro se tenía constante necesidad de ellos para defenderse contra los enemigos), son sentidos luego con reduplicada fuerza como peligrosos, cuando faltan los canales de derivación para ellos, y son tachados de inmorales y entregados a la difamación. Los instintos e inclinaciones antitéticos de ellos son los que alcanzan entonces los honores morales. El grado mayor o menor de peligro que para la comunidad, que para la igualdad hay en una opinión, en un estado de ánimo y un afecto, en una voluntad, en un don, eso es lo que ahora constituye la perspectiva moral. También aquí el miedo vuelve a ser el padre de la moral. Cuando los instintos más elevados y fuertes, irrumpiendo apasionadamente, arrastran al individuo más allá y por encima del término medio y de la hondonada de la conciencia gregaria, entonces el sentimiento de la propia dignidad de la comunidad se derrumba y su fe en sí misma, su espina dorsal, por así decirlo, se hace pedazos: en consecuencia, a lo que más se estigmatizará y se calumniará será a tales instintos. La espiritualidad elevada e independiente, la voluntad de estar sólo, la gran razón son ya sentidas como peligro. Todo lo que eleva al individuo por encima del rebaño e infunde temor al prójimo es calificado, a partir de este momento, de malvado. Los sentimientos equitativos, modestos, sumisos, igualitaristas, la mediocridad de los apetitos alcanzan ahora nombres y honores morales». MBM $\mathbb{} 201$.

17. MBM, $\mathbb{} 188$.

18. FP II parte $1,42[61]$. 
tienen ninguna fuerza de motivación realmente efectiva de nuestro comportamiento. El comportamiento está impulsado, en primera instancia, por impulsos y sentimientos. Y lo que tiene que hacer la educación moral, por tanto, es crear en los niños un determinado impulso de atracción o inclinación hacia lo establecido por la sociedad como bueno, y otro determinado impulso de rechazo y de aversión hacia lo establecido por la sociedad como malo. Esta es la razón de que las explicaciones y razonamientos morales no jueguen ningún papel esencial en el proceso de transmisión real de la moral en una sociedad determinada.

¿Cómo crea esta educación esos impulsos de atracción y rechazo que funcionarán ya toda la vida como motivaciones morales? Pues imponiendo a los individuos determinados hábitos, o sea, creando en ellos reacciones automáticas, espontáneas, inconscientes de aceptación o de rechazo ante determinadas situaciones. Si un niño ha hecho algo que está mal, se le da un bofetón para que no vuelva a repetir lo que ha hecho. De este modo, se le graba neurológicamente una respuesta de rechazo ante eso. Hasta seres queridos como los padres emplean con sus hijos el castigo corporal y el sufrimiento infligido física o psicológicamente, porque es el modo más eficaz de hablar directamente al cuerpo para que incorpore esas reacciones instintivas adecuadas de inclinación y de rechazo de tal modo que funcione ya de por vida como las instancias primeras de desencadenamiento de las acciones permitidas o de inhibición de las prohibidas por la sociedad: «Hacer del animal de rapiña humano, mediante la crianza (Züchtung), un animal doméstico, para lo cual la cultura ha tenido que utilizar como instrumento la más brutal violencia y represión ${ }^{19}$. Se nos ha creado de este modo una conciencia moral que nos hace responsables, o sea, obligados a responder de nuestros comportamientos ulteriores. Y el castigo, la pena, o el sufrimiento que se inflige después al autor de una falta o de un delito, no es otra cosa que el modo concreto de obligarle a que recupere la memoria de lo que debía o no debía hacer.

En resumen, la moralización es un proceso de educación que se nos ha impuesto con una disciplina muy estricta, en la que están frecuentemente incluidos el castigo corporal o la coacción psicológica, con el fin de conseguir que se nos grabe en nuestro cuerpo, que incorporemos, introduzcamos dentro y configuremos como estructura pulsional nuestra una regularidad espontánea en nuestros comportamientos que nos mantenga dentro de lo que la sociedad considera que es lo bueno, lo permitido y lo conveniente, y al margen de lo que considera que es lo malo, lo prohibido y perjudicial. De manera que, mediante la educación moral lo que se nos sigue imponiendo es la obligación imperativa de sumisión a ciertas costumbres y normas, es decir, lo que se pretende es lograr en nosotros formas de regularidad y de previsibilidad en nuestros comportamientos, exigiendo de nosotros que nos conformemos y adaptemos a lo comúnmente establecido y quede con ello neutralizada la posibilidad de que nos convirtamos en una excepción y, por tanto, en un peligro: «El adiestramiento del animal se obtiene en la mayoría de los casos debilitando al animal. Del mismo modo, el hombre moralizado no es un hombre mejor, sino debilitado, un hombre radicalmente disminuido y desfigurado, pero menos peligroso» ${ }^{20}$.

19. GM I $\$ 11$.

20. FP IV 15[55]. 
Naturalmente sería absurdo defender, a partir de un análisis que cargara el acento en la crueldad desplegada por buena parte de nuestros educadores tradicionales, defender, digo, que la educación moral debería quedar abolida para dejar que los niños y los individuos nos comportemos dejándonos llevar por nuestros impulsos naturales sin coacción ni represión. Esta es una idea absurda porque la vida humana, que ha de desarrollarse en sociedad, implica necesariamente un cierto autodominio estructural de ciertas pulsiones individuales sin el cual no es posible la convivencia, ni el trabajo, ni la comunicación, ni las relaciones entre las personas en general. En todas las sociedades, el proceso de hominización, o sea, el acceso a la cultura, y con él la superación de la animalidad, se ha llevado a cabo mediante un tipo u otro de educación moral, que es la encargada de dar forma al caos de los impulsos vitales naturales del individuo ${ }^{21}$. No ha habido, ni hay ninguna civilización humana que sea pura armonía y continuidad con la naturaleza. En armonía y continuidad con la naturaleza sólo están los grupos animales que no forman una sociedad ni una comunidad humanas. De modo que la cultura, o sea, la reordenación de los dispositivos pulsionales de los individuos y de sus instintos, es algo estructural, constitutivo del ser humano, y para culturizar al ser humano no hay más remedio que someterle a una disciplina coactiva externa que le programe y le configure sus impulsos.

Sin embargo, hay diversas formas posibles de hacer esto. Y lo que Nietzsche critica en nuestra moral occidental es que no ha elegido la mejor. ¿Por qué? Pues porque ha identificado la moralización con una mala desnaturalización. Cultura y naturaleza tienen que ser cosas distintas. Pero el que tengan que ser cosas distintas no implica que tengan que ser también incompatibles e irreconciliables. Lo que la moral occidental ha hecho ha sido contraponerlas drásticamente, y esto ha tenido consecuencias graves y posiblemente irreparables. ¿Por qué nuestra moral occidental ha identificado moralización con esta mala desnaturalización? Pues a causa de su prejuicio dualista metafísico y teológico que separa de modo radical naturaleza y espíritu, cuerpo y alma, hombre y animal. De este modo ha concebido al ser humano como sólo espíritu, sólo alma y sólo razón, y en modo alguno como un ser natural ${ }^{22}$.

21. "Costumbre y decencia: Ser moral, decente, ético significa prestar obediencia a una ley o tradición fundada desde antiguo. Es indiferente si uno se somete a ella de buen o mal grado, basta con que lo haga. Se llama bueno al que, por naturaleza, siguiendo una larga herencia y, por tanto, fácil y prestamente, obra lo decente, sea esto lo que sea (por ejemplo, tomándose la venganza cuando eso forma parte, como entre los antiguos griegos, de las buenas costumbres)... Malo es ser no decente, o sea, contravenir la tradición, sea ésta racional o estúpida. Pues da igual cómo haya nacido la tradición. En todo caso, sin atender a bueno y malo o a cualquier imperativo categórico inmanente, sino, ante todo, con el fin de la conservación de una comunidad, de un pueblo. Así, un uso supersticioso nacido sobre la base de un azar falsamente interpretado, impone una tradición que es decente seguir». HH I $\$ 96$.

22. «Sólo un ser racional posee la facultad de obrar por la representación de las leyes, esto es, por principios; posee una voluntad. Como para derivar las acciones de las leyes se exige razón, resulta que la voluntad no es otra cosa que razón práctica. Si la razón determina indefectiblemente la voluntad, entonces las acciones de este ser, que son conocidas como objetivamente necesarias, son también subjetivamente necesarias, es decir, que la voluntad es una facultad de no elegir nada más que lo que la razón, independientemente de la inclinación, conoce como prácticamente necesario, es decir, bueno». I. Kant, Fundamentación de la metafísica de las costumbres, cit., pp. 80-81. 
Recapitulando lo dicho y dirigiéndonos ya a fijar la respuesta a la cuestión que daba título a este trabajo: qué son y cómo se establecen los valores. Los valores son, como se deriva del modo en que los hemos adquirido por la educación, creencias interiorizadas que traducen las preferencias fundamentales de una sociedad o de una cultura determinadas respecto a qué debe ser lo prioritario, lo necesario, lo beneficioso así como, en sentido opuesto, lo perjudicial, lo superfluo, lo prescindible en el modo como esa sociedad se sitúa frente al mundo ${ }^{23}$. De modo que los valores son las interpretaciones más básicas sobre las que se fundamenta una cultura, y que expresan las necesidades idiosincrásicas del tipo de hombre que evalúa ligadas a su conservación y desarrollo ${ }^{24}$. Tienen, como ya comprendió Darwin, una vinculación muy estrecha con las pulsiones, instintos o afectos. En realidad, estas pulsiones, que se han configurado dentro del cuerpo de los individuos, son ya dispositivos creados como preferencias axiológicas respecto a la vida y la existencia, y están jerarquizados en función de estas preferencias. Es decir, los valores son tendencias incrustadas en la vida misma de nuestro cuerpo a través de ese proceso de grabación que ha producido en nosotros la educación. Y por eso son capaces de orientar nuestra conducta de manera imperativa, es decir, obligándonos a realizar cierto tipo de actos e impedir la realización de otros. De este modo, estos valores que tenemos incorporados, o sea, metidos en el cuerpo, regulan nuestro comportamiento con una seguridad incomparablemente mayor a como podría hacerlo la razón.

Naturalmente que tenemos, pues, dentro de nosotros una conciencia moral que nos dice en cada momento qué es el bien y qué es el mal. Lo que hay que tener claro es cómo ha entrado ahí. No porque nos la haya puesto Dios de manera innata, sino porque la han metido ahí coactivamente y la hemos incorporado en el proceso de socialización. Por esta razón, los valores pueden tener, para Nietzsche, el estatuto de síntomas del nivel de salud o de enfermedad del cuerpo social que los profesa, porque traducen y muestran el grado de fuerza de su voluntad de poder. Este grado de fuerza es lo que permite diferenciar entre unos valores y otros, y entre unos individuos y otros. La potencia o el poder de los valores es lo que confiere la elevación o la disminución del grado de existencia que proporcionan esos valores al individuo o a la sociedad que los acoge e incorpora.

Todo ser humano es esencialmente un ser de valores, y esto quiere decir que es un ser que percibe y valora en cada momento qué es lo que puede asimilar y dominar para sobrevivir y crecer, y qué es lo que puede ser para él una amenaza, un daño y un peligro. Tasar, o sea, fijar el precio, evaluar, imaginar equivalencias de valor entre unas cosas y otras, o entre unos hombres y otros, intercambiar productos o servicios... Todo esto constituye una de las actividades más básicas y omnipresentes entre los seres humanos de todos los tipos y de todas las culturas. Pues justamente esta es la actividad que produce la moral. Lo que expresa entonces el bien de una moral determinada, generalmente, son las condiciones de vida que los hombres que profesan esa moral estiman adecuadas y necesarias para su supervivencia y crecimiento, mientras que el mal designaría lo que debe

23. Cf. FP II parte 2, 11[20].

24. Cf. MBM $\$ 3$. 
ser evitado y excluido por ellos, y, por tanto, aquello por lo que se debe sentir una reacción de rechazo ${ }^{25}$. Esto es lo que significa una moral al servicio de la adaptación y el desarrollo de los seres humanos. No hay valores en sí, un bien y un mal absolutos que formen parte de la estructura del ser y con cuyo cumplimiento el ser humano se humaniza y encuentra su dignidad como persona. El hombre es el que produce sus valores, los instaura, lo mismo que produce el conocimiento, el arte o la técnica. Son una creación de cada sociedad al servicio de sus necesidades de supervivencia y desarrollo.

De ahí que Nietzsche crea posible que se pueda y se deba producir en nuestra época una transvaloración o inversión de los valores. En primer lugar, porque ya no vivimos en aquella situación de inseguridad y de miedo que dominaba en nuestros orígenes históricos, en la que había que imponer tiránicamente la obediencia y sumisión a unas costumbres gregarizadoras. Y, en segundo lugar, porque después de dos mil años hemos podido comprobar adónde nos ha conducido una moral occidental como la nuestra opuesta e incompatible con la naturaleza y con la vida. La crítica de Nietzsche a esta moral occidental se podría sintetizar en lo siguiente. Los valores morales que nuestra moral occidental nos ha hecho incorporar en el proceso de nuestra educación, junto con las reglas de conducta, las virtudes y los ideales de lo que se nos ha enseñado como lo que está bien y lo que está mal, rompen al ser humano al basarse en el dualismo metafísico y contraponer en él, en consecuencia, lo moral a lo natural. Por ello, estos son valores contrarios a la vida y a sus exigencias, y hunden al individuo en un conflicto interno que le debilita y le neurotiza. La vida, tal como la vemos en sus expresiones naturales, implica aspectos como la lucha, la crueldad, la injusticia, la desigualdad, el sufrimiento de los inocentes, la desgracia inmerecida y finalmente la muerte. Pues bien, todo esto lo estima nuestra moral occidental como algo que no debería ser así, que está mal. Se considera por ello que hace falta una moral que se enfrente a la vida para corregirla y reconvertir el ser de la vida en bien. Implícitamente, al menos, por tanto, para nuestra moral occidental esta vida es inmoral, porque depende en todo momento para su existencia y desarrollo de condiciones inmorales como el crimen, la muerte, la injusticia y el sufrimiento.

Lo que, sin embargo, se ha derivado, de hecho, de esta enemistad, de este conflicto y de este rechazo de la vida es que, después de más de veinte siglos de educación en esta moral, nos ha venido a invadir el nihilismo. Entonces lo que él se pregunta es qué pasaría si le diésemos la vuelta a esta moral nihilista, si la invirtiésemos y formuláramos nuevos valores propios de una moral de señores, o sea valores que no surgieran ya de la negación y del conflicto con la vida, sino de su afirmación, de su aprobación, incluso del agradecimiento hacia ella por su eterna singularidad, y de la admiración por su hermosura tal y como es, en su mezcla imponderable de bien y de mal ${ }^{26}$. Lo más aprovechable del pensamiento

25. «El valor de la vida está en las valoraciones: las valoraciones son algo creado, no son nada recibido, aprendido, experimentado. Lo creado ha de ser destruido para dejar lugar a lo nuevocreado: la viabilidad de las valoraciones implica su capacidad para ser destruidas. El creador debe siempre ser también un destructor. Sin embargo, el mismo valorar no se puede destruir: pues él no es otra cosa que la vida misma». FP III 5[1]234.

26. Para un desarrollo más detallado de esta propuesta me permito remitir a mi libro Nietzsche, la experiencia dionisíaca del mundo, Madrid: Tecnos, ${ }^{4} 2009$. 
de Nietzsche sobre la moral es, por tanto, entre otras cosas, la idea de que los seres humanos de nuestras sociedades avanzadas y modernas necesitamos cambiar nuestra noción de la moral y de la educación moral. Hay que crear nuevos valores que recojan aquello que puede ser capaz de realizarnos y de mejorar nuestra convivencia y nuestras condiciones de existencia. En este sentido, una propuesta que podría quedar simplemente apuntada y sugerida se vertebraría en torno a una idea que debería presidir este giro hacia una nueva moral. Y es la idea de que la nueva moral que necesitamos debería entenderse en conexión con la realización por parte de los individuos de su libertad y de su proyecto personal de vida.

La moral tradicional ha sido, hasta ahora, un instrumento para limitar, disminuir y reprimir la libertad de los individuos. Ahora la moral debería ser aquello que debería impulsar, guiar y orientar la realización de la propia libertad individual, ayudando a los individuos a alcanzar su edad adulta par formar una sociedad mejor, más sana, libre y feliz para todos. Toda la crítica de Nietzsche a la moral occidental está inspirada en esta posibilidad y se desarrolla al hilo de una muy interesante comparación entre valores morales y valores estéticos, y entre acción moral y acción artística, que ya no tenemos tiempo de desarrollar aquí y que dejamos para otra ocasión. 